\title{
Stakeholders' willingness to pay for enhanced construction waste management: a Hong
}

\section{Kong study}

Weisheng $\mathrm{Lu}^{1}$, Yi Peng ${ }^{2}$, Chris Webster ${ }^{3}$, and Jian $\mathrm{Zuo}^{4}$

1 Corresponding author, Assistant Professor, Dept. of Real Estate and Construction, the University of Hong Kong, Pokfulam, Hong Kong. Tel: (+852) 2859 7981, Email: wilsonlu@hku.hk.

2 Post-Doctoral Fellow, Dept. of Real Estate and Construction, the University of Hong Kong, Pokfulam, Hong Kong.

3. Chair Professor, Dean, Faulty of Architecture, the University of Hong Kong, Pokfulam, Hong Kong.

4. Senior Lecturer, School of Natural and Built Environments, University of South Australia, Adelaide, South Australia, Australia.

\begin{abstract}
Based on the polluter pays principle, construction waste disposal charging schemes (CWDCS) have been deployed by various economies as one of the most effective ways of managing construction waste. Nevertheless, a means of rationalizing these schemes has not been well documented. Using the economic technique of contingent valuation method (CVM), this study aims to investigate stakeholders' willingness to pay (WTP) for enhanced construction waste management (CWM) with a view to providing a scientific foundation for CWDCS rationalization. In considering this WTP in light of repeated exhortations that all stakeholders play a role in the management of construction waste, the study is unique. To ascertain stakeholders' WTP, a payment card-style questionnaire survey was designed and administered to Hong Kong's major CWM stakeholders in February 2014. Interestingly, the results show that there is no statistically significant variation in the WTP expressed by different stakeholder groups. The average maximum WTP is around HK $\$ 232 / \mathrm{t}$ for landfill disposal of construction and demolition (C\&D) waste, HK\$186/t for off-site sorting facility (OSF) disposal, and HK\$120/t for public fill reception facility (PFRF) disposal. These values are higher than the existing CWDCS charges $(\mathrm{HK} \$ 125 / \mathrm{t}$ for land filling, HK\$100/t for OSF disposal, and HK\$27/t for PFRF disposal) but much lower than the charges proposed to the government. This research provides not only a scientific foundation for the ongoing debate on changes to Hong Kong's CWDCS, but also a valuable reference for other economies facing the challenge of developing charging schemes to deal with construction waste.
\end{abstract}


Keywords: Construction waste management, waste charging, contingent valuation method, willingness to pay, Hong Kong

\section{Introduction}

Construction waste disposal charging schemes (CWDCS) have been deployed by various economies to manage construction waste. In this paper, the terms 'construction waste' and 'construction and demolition (C\&D) waste' are used interchangeably to refer to the surplus materials generated by site clearance, excavation, construction, refurbishment, renovation, and demolition. According to these schemes, waste disposal fees are devised and levied on those who dispose of construction waste in public landfills. Such fees may thus also be called landfill tax or landfill charging (Lu and Yuan, 2010). In Europe, landfill tax rates vary greatly from one country to another. In the UK, for example, a landfill tax was introduced in 1996: a standard rate for active waste and a lower rate for inactive waste. Currently, the active waste rate is $£ 72 / \mathrm{t}$ (US $\$ 199.8 / \mathrm{t}$ ) and the inactive waste rate is $£ 2.50 / \mathrm{t}$ (US\$4.16/t) (Maccioni, 2013). Austria charges $€ 9.20 / \mathrm{t}$ (US\$12.6/t) of construction material and soil deposited in landfills. Finland charged $€ 40 / t$ (US\$54.9/t) as of 2011 , with a rise to $€ 50 / t$ (US\$68.7/t) planned in 2013. Meanwhile, C\&D waste land filling is banned in the Netherlands (Cambridge Econometrics, 2013). In Queensland, Australia, a levy of AU\$35/t (US\$32.4/t) of C\&D waste has been imposed since December 2012 (ASBG, 2012). The National Environment Agency of Singapore charges S\$77/t (US\$57/t) of waste disposed (Cooper, 2013).

It has been reported that CWDCS are a very effective way of not only reducing waste but also promoting the reuse and recycling of waste materials (Andersen, 1998; Glazyrina et al., 2006; Hao et al., 2008; Lu and Tam, 2013). Nevertheless, the rationale behind some CWDCS is not without question. Yuan and Wang (2014) reported that China's CWDCS have largely been determined according to a rule of thumb rather than the findings of scientific investigation. Their study used a system dynamics model to determine that the maximum construction waste disposal charge in Shenzhen, Southern China should be $¥ 80 / \mathrm{t}$ (US\$12.9/t) (Yuan and Wang, 2014). Begum et al. (2007) 
used contingent valuation method (CVM) as their theoretical foundation for investigating how much construction contractors would be prepared to pay for improved construction waste management (CWM) in Malaysia. The study assessed the average maximum willingness to pay (WTP) for improved CWM to be RM69.88/t (US\$21.4/t). Further examples of research on construction waste disposal charges are scarce, particularly when compared to the volume of existing research on municipal solid waste (MSW). This maybe attributed largely to the inherent complexity of such charging.

Construction is not by its nature an environmentally friendly activity ( $\mathrm{Lu}$ and Tam, 2013); the waste produced contributes significantly to environmental degradation (Coelho and de Brito, 2012; Li et al., 2014; Lu and Yuan, 2010). If not reused or recycled, construction waste ends up in landfills, where its anaerobic degradation leads to air pollution and contamination of the soil and groundwater. Landfills compete for space and give rise to "Not In My Back Yard" (NIMBY) syndrome, particularly in economies with compacted urban space such as Hong Kong, Singapore and Japan. Both the natural environment and any urban space saved via reduced land filling are, in economist's terms, public goods subject to free rider problems. If the environmental cost of construction is not fully internalised by devices such as a landfill tax, then it is an externality; a social cost not included in the cost-benefit calculus that drives city-building ( $\mathrm{Lu}$ and Webster, 2014). However, the natural environment is a typical non-market good which cannot be easily priced. As will be illustrated later, attempting to set a construction waste disposal charge by calculating the externalities of CWM on an urban or community scale is difficult, if not completely unrealistic.

A further complication in CWM is the involvement of stakeholders. To provide context, stakeholders in MSW management include the general households in a community. By contrast, the stakeholders in CWM are 'a manageable few' including clients, architects, contractors and material suppliers organised in companies and professional bodies. However, CWM stakeholders are not as homogeneous as their counterparts in MSW management; they comprise different interest groups. Without full consideration of their diverse interests, a CWM policy is ultimately likely to fail. Grandy 
(1994) pointed out that engaging stakeholders in policymaking will inevitably involve them in the 'politics of urban waste'. Even so, to go anywhere with the directions of politics or economics, an analysis of stakeholders' stance (e.g. willingness to pay) must be properly conducted to provide at least a certain degree of scientific foundation for a CWDCS.

The aim of this study is to investigate stakeholders' willingness to pay for CWM by examining Hong Kong's construction industry. It is conducted at an opportune time; to deal with its acute CWM issues, Hong Kong is currently considering raising its construction waste disposal charges. The study has both academic and practical values. It contributes to the ongoing debate surrounding the application of economic tools such as CVM to the pricing of public goods like environment protection. Practically, it provides a scientific foundation for the formulation of CWM policies. The remainder of the paper comprises five sections. Section 2 is a review of the literature on stakeholder involvement in CWM, economic rationales for CWDCS, and CWM in Hong Kong. Section 3 describes the research design, which is a payment card-style questionnaire survey for major stakeholders involved in CWM in Hong Kong. Analyses and results are reported in Section 4. In Section 5, the results are discussed, and conclusions and policy implications are drawn in Section 6.

\section{Literature review}

\subsection{Stakeholders' involvement in construction waste management}

According to stakeholder theory founded by Freeman (1984), stakeholders have different interests in a system and thus have different impacts upon it, positive or negative, and the system responds to their interests. Stakeholder management is about how stakeholders are identified, classified, considered and subsequently managed (Freeman, 1984; Carroll and Buchholtz, 2000; Welp et al., 2006), with the purpose of addressing diverse views of participants, improving communication among stakeholders, and clarifying their needs (Freeman, 1984; Mitchell et al., 1997). Although numerous methods and tools have been suggested for identifying stakeholders (e.g. Cleland, 1986; Walker et al., 2008), it remains difficult. In an abroad sense, a stakeholder is "any identifiable group or individual who can affect the achievement of an organisation's objectives or who is affected by the achievement of the 
organisation's objectives" (Freeman, 1984). In a narrow sense, stakeholders are those groups or individuals that an organisation depends upon for its continued survival. There are other stakeholder typologies. For example, primary stakeholders are those ultimately affected, either positively or negatively, by an organisation's actions. Secondary stakeholders are the 'intermediaries'; persons or organisations who are indirectly affected by an organisation's actions. Applying the typologies, stakeholders in CWM can be identified as: (1) public or private clients, (2) designers (e.g. architects and engineers), (3) consultants, (4) main contractors, (5) sub-contractors and material vendors, (6) C\&D recyclers, (7) regulators, (8) environmentalists, and (9) the general public.

Increasingly, the importance of managing stakeholders when dealing with construction waste is being recognised. Alamgir et al. (2012) clearly stated that successful waste management strategies require the meaningful involvement of concerned stakeholders. Research on CWM has focused on contractors and subcontractors as the frontline stakeholders (Skoyles, 1976; Poon et al., 2001; Lu et al., 2011). Clients are envisaged to play a pivotal role in CWM, as ultimately they pay for the construction waste that is generated. Subcontractors or material vendors now face extended producer responsibility (EPR) which means that they are responsible for the waste (e.g. packaging) generated from their supplies (Wang et al., 2014). Hyder Consulting (2011) found extensive stakeholder engagement, with over 110 organisations potentially affecting or being affected by the enactment of CWM public policy in Australia. Gradually, it is accepted that these stakeholders can legitimately participate in the making of such policies, including the deployment of CWDCS.

\subsection{Economic rationales for construction waste disposal charging schemes}

Construction waste disposal charging schemes (CWDCS) were largely based on the polluter pays principle (PPP), whereby the polluter pays for damage caused to the natural environment. The PPP has inspired most modern environmental legislation (Duran et al., 2006), in particular in the Organisation for Economic Co-operation and Development (OECD) countries (Hao et al., 2008). In the case of construction waste, private contractors would benefit from low landfill tax while societies incur a high environmental cost (Duran et al., 2006). CWM, in economics terms, has a typical free rider problem. 
CWDCS are a means by which policy makers address this problem by trying to internalize the externality and ensuring that polluters incur the external costs (Craighill and Powell, 1999). Some important works have outlined a concept that links the PPP and economics models for the development of CWDCS (e.g. Mills et al., 1999; Craighill and Powell, 1999; Begum et al., 2006; Duran et al., 2006).

Complicating the application of the PPP to CWM is contractors' argument that they are not ultimate polluters but simply providers of services to construction clients. Notably, Lu et al. (2009) proposed a stakeholder pays principle (SPP), whereby every responsible stakeholder should pay for the damage to environment. An application of this principle would not mean the imposition of levies on all stakeholders individually; as suggested by interviewees in the study, this would create high enforcement costs. Rather, CWDCS would be channelled to all stakeholders to encourage joint CWM efforts, resulting in less construction waste. In practice, contractors do include C\&D waste levies as a separate cost item in bidding, and clients seem to acquiesce to this practice. The effects of CWDCS have been channelled back to construction sites to encourage contractors to practice better CWM such as on-site sorting, but few behaviour changes have been observed amongst subcontractors (Yu et al., 2012; Yuan et al., 2013).

After ascertaining who should pay, the question remains how much should be paid. To answer this question, it would seem logical to conduct a cost-benefit analysis (CBA) of CWM and derive a charge level that can balance the costs and benefits, e.g. Begum et al. (2007) and Coelho and de Brito (2012). These studies provide useful insights into the economic aspects of a relatively confined entity in the CWM chain. However, the scope of CWDCS is often regional, and this makes identifying costs and benefits more complicated while some external costs are usually missed in a CBA. To address this problem, researchers view externality as a more powerful concept, e.g. Chung and poon (1997) and the European Commission (EC) (2000). Externalities have been defined as "the costs and benefits which arise when the social or economic activities of one group of people have an impact on another, and when the first group fails to fully account for their impact" (EC, 2000). However, largely owing to 
the lack of reliable data, there are many uncertainties in valuing externalities, which in turn hampers the generation of a reasonable waste charging level. Therefore, researchers and policymakers have turned to contingent valuation method (CVM).

Resources such as environmental preservation or the impact of air pollution give people utility, but certain aspects of them do not have a market price as they are not directly sold. CVM is a survey-based economic technique for the valuation of these non-market resources with passive use value. The method often provides respondents with hypothetical goods or scenarios (e.g. different construction waste disposal arrangements) and solicits their stated preference (e.g. willingness to pay) for the goods or scenarios (Mitchell and Carson, 1989). There is a contentious debate over CVM, including whether measuring people's WTP for environmental protection plays any useful role (Bernad-Beltrán et al., 2014; Breffle et al., 2015). Carson et al. (2001) systematically reviewed the controversies on CVM and concluded that many of the alleged problems with CVM can be resolved through careful study design and implementation. This resonated with the investigation results published by a panel of high profile economists convened under the auspices of the National Oceanic and Atmospheric Administration (NOAA) in response to criticisms of CVM surveys: such surveys could be a useful tool for revealing the passive use values if applied carefully. CVM is gaining credibility and acceptance (Bateman and Turner, 1993). It is listed as a recognised technique by the US Department of the Environment, and is a major evaluation method for non-market goods in the US. CVM has thus been adopted in this study to investigate stakeholders' willingness to pay for enhancing CWM.

\subsection{Construction waste disposal charging in Hong Kong}

Based on the polluter pays principle, the Hong Kong Government implemented a Construction Waste Disposal Charging Scheme (CWDCS) in 2006. In line with this scheme, a construction contractor is levied HK\$125 for every ton of construction waste it disposes of at landfills, HK\$100 per ton of construction waste accepted by off-site sorting facilities (OSFs), and only HK\$27 per ton of waste consisting entirely of inert materials and accepted by public fill reception facilities (PFRFs). The 
CWDCS has significantly slowed the depletion of landfills in Hong Kong. It was found that due to the enactment of the CWDCS (Hao et al., 2008). This strengthens the belief that "attempts to significantly reduce waste generation would not be possible in the absence of major economic incentives to drive the requisite behavioural change" (HKEPD, 2012).

Nevertheless, even after the successful implementation of the CWDCS in 2006, CWM in Hong Kong remains "a gloomy situation" (Lu and Tam, 2013; Poon et al., 2013). Little improvement has been witnessed since, and the social-economic environment for CWM in Hong Kong has changed. For example, in the past, a considerable amount of inert material was transported to adjacent cities for land reclamation. In addition to controversies over the ethical grounds for doing so (Lu, 2013), transporting processed construction waste to Mainland China is more difficult since China tightened its regulations (Wong, 2013). There have been warnings that Hong Kong's landfills, planned to last until 2020, could be full several years earlier if nothing is done to reduce waste loads (HKEPD, 2012). At the same time, finding new landfill and PFRF sites in this compact city is extremely difficult due to strong opposition from residents and district councillors. There is an acute need for Hong Kong to become self-sufficient in managing its construction waste.

Within this context, the Government is considering enhancing CWM in Hong Kong by revisiting the current CWDCS. The Hong Kong Green Building Council (HKGBC) and the Business Environment Council (BEC) have recently formed a joint working group (JWG) with the aim of gathering views from industry stakeholders and drawing consensus on targets and recommendations for the reduction of construction waste. The JWG has involved a wide range of stakeholders in the construction sector to discuss the CWDCS. However, it has been observed that there was a general lack of scientific foundation for the group discussions. It is against this backdrop that this research was conducted, not on behalf of the JWG but as an independent endeavour funded by the Public Policy Research Scheme in Hong Kong.

\section{Research design and data collection}


A contingent valuation survey soliciting stakeholders' willingness to pay (WTP) is a useful tool only if applied carefully. In designing such a survey, there are two typical approaches: (a) the payment card version (Mitchell and Carson, 1989), whereby each respondent is provided with a list of monetised passive use values and is asked to circle the maximum amount he/she is willing to pay for the values, and (b) the referendum version, whereby individual respondents are asked to vote 'yes' or 'no' to a random selection of amounts and the vote is repeated until the maximum amount of WTP is identified. The NOAA panel seemed to recommend the referendum approach using personal interviews, whilst Blaine et al. (2005) reported that "neither approach emerges as unambiguously superior". In order to effectively approach the busy stakeholders involved in construction waste management (CWM) policymaking, this research used the payment card approach rather than referendum.

In view of widespread survey fatigue in the construction sector (Lu et al., 2009), the questionnaire was purposely designed to be succinct for easy completion. It has three parts. The first is a cover letter outlining the current CWM situation, the background to Hong Kong's CWDCS and the urgency of revisiting it. Ethical approval was obtained beforehand and the cover letter informs respondents that their participation is entirely voluntary, their identities will not be recorded, and all data will be kept strictly confidential and used solely for academic research purposes. The second part, also the main body of the questionnaire, comprises four required questions. Question 1 asks respondents to choose the option that best describes them as a stakeholder, e.g. government officer, client. Questions 2 to 4 were designed to solicit stakeholders' WTP. These three separate questions were included in view of the likelihood that the revisited CWDCS will continue to impose different levies on the three types of construction waste. Further, to alleviate possible starting point bias, an 'open-ended' question labelled 'other' was included after each question to allow respondents to fill in their own values (Boyle et al., 1985). The third part of the questionnaire is an open-ended optional question soliciting respondents' other views about Hong Kong's current and future CWDCS.

The questionnaire was designed using Google Docs as it could then be administered to respondents via email. A back-end MS Excel database automatically stored responses without recording identity 
information. To encourage more respondents, the questionnaire was drafted bilingually in English and traditional Chinese. The questionnaire was piloted in an MSc class with an enrolment of thirty middle-level or frontline practitioners in construction. As a result of the pilot study, some changes were made, e.g. providing a lower charge option than the original in order to reduce starting point bias (Boyle et al., 1985). The questionnaire was then administered to 250 potential respondents on the research team's contact list, including members of the abovementioned JWG, between 22 February 2014 and 31 March 2014. Unlike WTP surveys for MSW, which often involve a large number of autonomous households, this questionnaire was administered only to significant stakeholders in CWM, who will normally represent their respective organisations in the CWM policymaking process.

\section{Results and discussion}

\subsection{Brief summary of the responses}

In order to elicit stakeholders' WTP for enhanced CWM, they were categorised into different groups as follows: Group A-contractors; Group B-other construction industry practitioners such as clients, developers, consultants, sub-contractors/suppliers, and designers; Group C-government departments; and Group D - the general public. In total, there were 59 valid responses returned, representing a return rate of $23.6 \%$, which appears to be a standard response rate for questionnaire surveys in Hong Kong. As shown in Figure 1, of the 59 valid responses, 15.3\% (9) are in Group A, 39\% (23) are in Group B, 20.3\% (12) are in Group C, and 25.4\% (15) are in Group D.

$<$ Please Insert Figure 1 Here $>$

Table 1 summarizes the stakeholders' maximum WTP values (HK\$ per ton) and their respective frequencies for C\&D waste disposed of at landfills. In Group A, $22.3 \%$ reported a maximum WTP value of $\mathrm{HK} \$ 350 / \mathrm{t}$, while the reminder expressed an equal WTP of $\mathrm{HK} \$ 100,125,150,175,200,250$ and 300/t. The value of HK\$100 is, in fact, lower than the existing charge level. The contractor did not explain in the open-ended question why a lower charge should be imposed. The other contractors were 
willing to pay more than the existing charge level, but none were willing to pay a rate higher than HK\$350/t. In Group B, comprised of other construction industry practitioners, 39.2\% expressed a WTP of HK\$250/t, $17.5 \%$ reported a WTP value of $\mathrm{HK} \$ 175 / \mathrm{t}$, and $13 \%$ reported a WTP value of HK\$200/t. Group B's responses are more diverse than the contractors' (Group A's), probably showing a high level of difference amongst views on how much they should pay for the disposal of C\&D waste. A high percentage (33.3\%) of Group C (government respondents) suggested a WTP level of HK $\$ 350 /$ t. As shown in Table 1, Group D (the general public) also expressed diverse WTP values for disposal of construction waste at landfills.

$<$ Please Insert Table 1 Here $>$

Table 2 summarizes the stakeholders' maximum WTP values $(\mathrm{HK} \$ / \mathrm{t})$ and their respective frequencies for C\&D waste disposed of at off-site sorting facilities (OSFs). Given the compact site areas in Hong Kong or for other reasons (e.g. deeming on-site sorting less economical), contractors can send their construction waste, often in the form of a mixture of both inert and non-inert substances, to the OSFs for further segregation. The impact of this practice on the natural environment is considered to be less severe than land filling, therefore the charging level at the OSFs (HK\$100/t) is lower than at landfills $(\mathrm{HK} \$ 125 / \mathrm{t})$. Stakeholders in Group A expressed different levels of WTP for the construction waste disposed of at an OSF. Of the responding contractors, $22.2 \%$ suggested $\mathrm{HK} \$ 75 / \mathrm{t}$, a lower WTP than the existing charging level, while $33.4 \%$ suggested a moderate increase to HK\$150/t. Interestingly, the largest percentage of respondents from Group B suggested the same level of HK\$150/t. In Group C, $50 \%$ of the respondents suggested a level of HK\$200/t, while Group D's (the general public's) expressed WTP for disposing of construction waste at OSFs is diverse.

$<$ Please Insert Table 2 Here $>$

Table 3 summarizes the stakeholders' maximum WTP values $(\mathrm{HK} \$ / \mathrm{t})$ and their respective frequencies for C\&D waste disposed of at public fill reception facilities (PFRFs). Only inert construction waste is 
received at PFRFs and the charge is HK\$27/t due to the perceived minimal impact on the natural environment. It can be seen from Table 3 that the majority (44.5\%) of Group A respondents suggested an unchanged WTP level of HK\$27/t, while none are willing to pay more than $\mathrm{HK} \$ 125 / \mathrm{t}$. The majority of respondents from Group B (26.2\%), Group C (41.7\%), and Group D (46.6\%) are willing to pay HK $\$ 50$ for each ton of construction waste disposed of at a PFRF.

$<$ Please Insert Table 3 Here $>$

\subsection{Average maximum willingness to pay (WTP) for C\&D waste disposal}

Table 4 summarizes the mean and standard deviation (SD) value of the maximum WTP expressed by each stakeholder group for each method of waste disposal. As shown in Table 4, the contractor group (Group A) stated the lowest level of WTP for each of the C\&D waste disposal approaches. This reflects the common practice whereby only the main contractors pay the $C \& D$ waste disposal charges; therefore their preference is to keep these charges as low as possible. Although the landfill charge can theoretically be included in the bid for a project, the fact that Hong Kong's construction market usually awards its contracts to the lowest bidder is as a disincentive to do so. The general public (Group D) did not state the highest level of WTP for any of the types of C\&D waste disposal. This is possibly due to their lack of awareness about the seriousness of Hong Kong's C\&D waste disposal problems, in contrast to the high level of public concern regarding MSW.

$<$ Please Insert Table 4 Here $>$

It can also be observed from Table 4 that stakeholders from government departments (Group C) expressed the highest level of WTP for C\&D waste disposed at landfills. This is not unexpected as the government shoulders the burden of managing public goods. In particular, it is under pressure to protect the environment and find new landfill sites given that existing landfills, planned to last until 2020, could be full several years earlier if nothing is done to reduce waste loads (HKEPD, 2012). Of the four types of stakeholders, Group B (other construction industry practitioners) stated the highest 
level of WTP for disposal of C\&D waste at OSFs and PFRFs. This reflects the serious shortage of OSFs and PFRFs in Hong Kong. More than $90 \%$ of construction waste generated is inert waste; in 2011, PFRFs received 17,579,860 tons of inert C\&D waste, around 15 times the amount of non-inert C\&D waste received by landfills in Hong Kong.

Analysis of variance (ANOVA) was conducted to examine whether the different stakeholder groups would state different levels of WTP for enhancement of CWM. ANOVA is a collection of statistical models, pioneered by Fisher (1925), which can be used to analyse the differences between group means and their associated procedures. If a probability value $p$ from an ANOVA test is below 0.05 , it normally suggests that a high degree of difference of opinion exists among the groups. The ANOVA was conducted with Statistical Package for the Social Sciences (SPSS). The results are shown in Table 5. It was found that none of the $p$ values is below 0.05 , suggesting statistically no significant difference among the four stakeholder groups; namely, contractors, other construction industry practitioners, government departments, and the general public.

$<$ Please Insert Table 5 Here $>$

Given that statistically there is no significant difference amongst the maximum WTP expressed by different stakeholder groups, it makes sense to average the WTP. Table 6 shows the mean values and SD of WTP expressed by all stakeholders. As a homogeneous group, they reported WTP about HK\$232/t to dispose of C\&D waste at landfills, HK\$186/t at OSFs, and HK\$120/t at PFRFs. These levels of WTP are all higher than the existing charges. According to the CWDCS enacted in 2006 (HKEPD, 2006), a contractor is charged HK\$125/t for disposal of C\&D waste at landfills, HK $\$ 100 / \mathrm{t}$ at OSFs, and HK\$27/t at PFRFs. However, the WTP levels shown in Table 6 are much lower than the charges proposed to the government. In the Policy Report produced in October 2013 and subsequently submitted to the government, the aforementioned JWG formed by the HKGBC and the HKBEC suggested charges of $\mathrm{HK} \$ 125, \mathrm{HK} \$ 700$ and $\mathrm{HK} \$ 1,200$ for disposing of a ton of construction waste in landfills in 2015, 2020 and 2025 respectively. 
$<$ Please Insert Table 6 Here $>$

\section{Discussion}

\subsection{Stakeholder management}

It is widely recognized that all stakeholders, in managing $C \& D$ waste, play a critical role in achieving a sustainable built environment (e.g. Lu et al., 2009; Alamgir et al., 2012). A typical construction project involves a large number of stakeholders, including clients, contractors, design consultants, engineers, and the general public. All of these stakeholders should be motivated to engage in CWM (Manowong, 2012). This study is probably the first to investigate these stakeholders' WTP for CWM by capturing their similarities and differences. It is encouraging to discover that all stakeholders express a level of WTP for enhancement of CWM that is higher than the existing waste disposal charges. This indicates stakeholders' awareness of issues associated with C\&D waste disposal and their commitment to its improvement. This resonates with reporting that the proper management of C\&D waste has been accepted by contractors and other stakeholders as a corporate social responsibility (Zhao et al., 2012).

The discrepancies between different stakeholders in WTP must be given serious attention. As previously asserted, a failure to fully consider all stakeholders' interests in the formulation of a CWM policy will ultimately lead to its failure. This research effectively identifies various stakeholders' views (including, for example, which stakeholders are the most influential supporters or opponents), and thus offers a scientific foundation for stakeholder management. Stakeholder engagement is perceived as an effective way to align the different levels of WTP for enhancement of CWM. Effective communication is also essential (Osmani et al., 2008; Yuan, 2013); it is paramount to have a mechanism in place to ensure effective communication between project stakeholders on roles and responsibilities in CWM. A collaborative approach would help alter contractor's CWM behaviour (Sieffert et al., 2013). Under such an approach, incentives can be provided for initiatives aimed at optimal CWM performance, whereby cost savings are distributed to stakeholders that propose and/or implement these initiatives. 
Furthermore, subsidies can be provided to bridge the discrepancies in WTP and encourage active engagement of all stakeholders in CWM. This research provides empirical data for calculating such subsidies.

Having expressed a higher WTP, some stakeholders in the open-ended optional question pointed out that a landfill tax should not be the only means employed to enhance CWM. Regardless of how high the taxes are, a certain amount of C\&D waste will still be generated. Lu (2013) critiqued CWM in Hong Kong, claiming that it is stuck in an inert/non-inert dichotomy whereby segregated inert and non-inert construction waste is dealt with using different strategies (e.g. landfills, piling for further reuse, or shifting to other regions for land reclamation). Hong Kong should move beyond this dichotomy and develop a recycling industry that can effectively process both inert and non-inert waste (Lu, 2013). This research has allowed stakeholders to look beyond waste disposal charging and voice their views on other waste management approaches.

\subsection{CVM methodological issues}

The research provides a valuable reference for the implementation of CVM in environment protection, e.g.in CWM. Firstly, compared to the vast amount of stakeholders/households in MSW, there are only a limited number of stakeholders in CWM to be solicited using CVM. While this means that there is potential to adopt a referendum approach using personal interviews, this research suggested that a payment card approach using questionnaire survey would be more convenient as stakeholders in CWM are often difficult to contact for the purpose of interviewing. The research does not speak to the superiority of either the payment card or referendum approach but takes Blaine et al.'s (2005) stance that neither approach is unambiguously better. Secondly, using a web-based questionnaire survey is an effective way of dealing with survey fatigue in the construction industry given the ubiquity of Internet access (Lu et al., 2009). However, respondents still should not be overwhelmed with too many questions in a CVM payment card style questionnaire survey. Keeping the questionnaire simple is critical to the success of the CVM approach. Some respondents in this study commented on the simplicity of the questionnaire; if it had been more complex, they would not have had the patience to 
complete it. Thirdly, in the payment card style questionnaire survey, it is essential to communicate clearly the programme to be offered and its consequences to allow the respondents to make an informed choice. In Hong Kong, the CWDCS has been operating for more than seven years, which suggests that respondents would possess sufficient information to ensure the quality of the survey; nevertheless, some professionals still struggled when completing the questionnaire with the impact of changing waste charges, e.g. they were unclear about the volume of a ton of C\&D waste.

\section{Conclusions and policy implications}

Construction and demolition (C\&D) waste has become a critical issue due to the volume of construction activity being undertaken globally. As a result, much effort has been put into improving waste management in the construction industry. Construction waste disposal charging schemes (CWDCS) have been recognized as one of most effective approaches for managing C\&D waste. This study explores stakeholders' attitudes towards CWM in the Hong Kong construction industry with the aim of rationalizing the CWDCS. The findings show that for C\&D waste disposal at landfill, off-site sorting facilities, and public fill reception facilities, construction-related stakeholders are willing to pay on average $\mathrm{HK} \$ 232, \mathrm{HK} \$ 186$, and $\mathrm{HK} \$ 120$ per ton respectively. It is interesting to note that these figures are higher than the existing standard in Hong Kong's CWDCS for each method of C\&D waste disposal.

This study has both academic and practical implications. Academically, the study contributes to ongoing debate regarding the application of economics tools such as contingent valuation method (CVM) to the pricing of public goods and environment protection measures. CVM is found to be a valuable tool for understanding stakeholders' attitudes toward sustainability measures. Practically, this study provides a scientific foundation and input for policymaking processes. The findings imply that the government should actively enhance public awareness of the impacts of C\&D waste disposal. In parallel, the level of $C \& D$ waste disposal charging should be raised due to the higher mean value of WTP compared to the existing standard specified in the charging scheme. It is essential to apply a stakeholder pays principle (SPP) whereby each responsible stakeholder pays for the environmental 
load of their activities. The SPP provides a useful tool for channelling CWDCS to all related stakeholders so that they will be proactively engaged in CWM.

Previous studies using CVM to assess MSW charging schemes have tended to link the reported WTP to the respondents' profiles such as gender, age, education, and income using regression models. This is very helpful in gaining insights into the WTP. However, this research believes it too early to model the profiles of CWM stakeholders; just understanding their WTP is the essential step at this stage. A limitation associated with this study is the comparatively small size of the sample. Future research could focus on the evaluation of stakeholders' WTP for improvements in CWM practice using a larger number of responses. This would allow modelling of stakeholders' WTP according to variables such as respondent profession, type of project, and procurement approach.

\section{Acknowledgement}

The research was supported by the Hong Kong Research Grants Council (RGC) Public Policy Research (PPR) Scheme (RGC Ref. HKU7016-PPR-11) and the National Nature Science Foundation of China (NSFC) (Project no.: 71273219).

\section{References}

Alamgir, M., Bidlingmaier, W., Cossu, R., 2012. Successful waste management strategies in developing countries require meaningful involvement of the concerned stakeholders. Waste Manag. 32(11), 2007-2008.

Andersen, M.S., 1998. Denmark's waste taxes. Environ. 40, 38-41.

ASBG, 2012. Review of the Waste and Environment Levy. Australian Sustainable Business Group, Sydney.

Bateman, I.J., Turner, R.K., 1993. Valuation of the environment, methods and techniques: the contingent valuation method. In Turner, R.K. (ed.) Sustainable Environmental Economics and Management: Principles and Practice, Belhaven Press, London.

Begum, R.A., Siwar, C., Pereira, J.J., Jaafar, A.H., 2007. Factors and values of willingness to pay for 
improved construction waste management - A perspective of Malaysian contractors. Waste Manag. 27(12), 1902-1909.

Bernad-Beltrán, D., Simó, A., Bovea, M.D., 2014. Attitude towards the incorporation of the selective collection of biowaste in a municipal solid waste management system: A case study. Waste Manag. 34, 2434-2444.

Blaine, T.W., Lichtkoppler, F.R., Jones, K.R., Zondag, R.H., 2005. An assessment of household willingness to pay for curbside recycling: A comparison of payment card and referendum approaches. J. Environ. Manag. 76(1), 15-22.

Boyle, K.J., Bishop, R.C., Welsh, M.P., 1985. Starting point bias in contingent valuation bidding games. Land Econ. 61(2), 188-194.

Breffle, W.S., Eiswerth, M.E., Muralidharan, D., Thornton, J., 2015. Understanding how income influences willingness to pay for joint programs: A more equitable value measure for the less wealthy. Ecol. Econ. 109, 17-25.

Cambridge Econometrics (2013). Modelling Milestones for Achieving Resource Efficiency: Economic Analysis of Waste Taxes: Draft Report for the European Commission (DG Environment). Cambridge Econometrics.

Carroll, A. B., Buchholtz, A. K., 2000. Business \& Society: Ethics and Stakeholder Management. South-Western Publishing, Cinn., Ohio.

Carson, R.T., Flores, N.E., Meade, N.F., 2001. Contingent valuation: Controversies and evidence. Environ. Resour. Econ. 19(2), 173-210.

Chung, S.S., Poon, C.S., 1997. Quantifying externalities in solid waste management in Hong Kong. J. Environ. Eng. 123(3), 282-289.

Cleland, D.I., 1986. Project stakeholder management. Proj. Manag. J. 17(4), 36-44.

Coelho, A., de Brito, J., 2012. Influence of construction and demolition waste management on the environmental impact of buildings. Waste Manag. 32(3):532-541.

Cooper, J., 2013. Taking recycling lessons from super Singapore. Waste Manag. World. http://www.waste-management-world.com/articles/print/volume-11/issue-5/features/taking-recyc ling-lessons-from-super-singapore.html (retrieved on 27-Feb-2014). 
Craighill, A., Powell, J.C., 1999. A lifecycle assessment and evaluation of construction and demolition waste. CSERGE Working Paper, WM 99-03.

Duran, X., Lenihan, H., O'Regan, B., 2006. A model for assessing the economic viability of construction and demolition waste recycling - the case of Ireland. Resour. Conserv. Recycl. $46(3), 302-320$.

European Commission, 2000. A Study on the Economic Valuation of Environmental Externalities from Landfill Disposal and Incineration of Waste: Final Main Report. DG Environment: EC.

Fisher, R.A., 1925. Statistical Methods for Research Workers. Edinburgh, United Kingdom, Oliver \& Boyd.

Freeman, E., 1984. Strategic Management: A Stakeholder Approach. Pitman, Boston, MA.

Glazyrina, R., Glazyrin, V., Vinnichenko, S., 2006. The polluter pays principle and potential conflicts in society. Ecol. Econ. 59, 324-330.

Grandy, M., 1994. Recycling and the Politics of Urban Waste. London, Earthscan.

Hao, J.L., Hills, M.J., Tam, V.W.Y., 2008. The effectiveness of Hong Kong's Construction Waste Disposal Charging Scheme. Waste Manag. Res. 26(6), 553-558.

Hong Kong Environmental Protection Department (HKEPD) (2012). Hong Kong Environment 2012. Hong Kong Government, 2012.

Hyder Consulting, 2011. Management of Construction and Demolition Waste in Australia. Department of Sustainability, Environment, Waste, Population and Communities. Queensland Department of Environment and Resource Management.

Li, Z.D., Shen, G.Q.P., Alshawi, M., 2014. Measuring the impact of prefabrication on construction waste reduction: An empirical study in China. Resour. Conserv. Recycl. 91, 27-39.

Lu, W.S., 2013. Beyond the inert and non-inert dichotomy: towards 'building a zero waste Hong Kong'. Build. J. 13, 46-49.

Lu, W.S., Tam, V.W.Y., 2013. Construction waste management policies and their effectiveness in Hong Kong: A longitudinal review. Renew. Sustain. Energy Rev. 23, 214-223.

Lu, W.S., Yuan, H.P., 2010. Exploring critical success factors for waste management in construction projects of China. Resour. Conserv. Recycl. 55(2), 201-208. 
Lu, W.S., Li, H., Shen, L.Y., Huang, T., 2009. A SWOT analysis of Chinese construction companies in the global market. , ASCE J. Manag. Eng. 25(4), 166-176.

Lu, W.S., Yuan, H.P., Li, J.R., Hao, J.L., Mi, X.M., Ding, Z.K., 2011. An empirical investigation of construction and demolition waste generation rates in Shenzhen city, South China. Waste Manag. 31(4), 680-687.

Maccioni, A., 2013. UK landfill tax is set to rise fast. Triple Pundit, 2nd December 2013, http://www.triplepundit.com/2013/12/uk-landfill-tax-set-rise-fast/ (retrieved on 26-Feb-2014).

Manowong, E., 2012. Investigating factors influencing construction waste management efforts in developing countries: an experience from Thailand. Waste Manag. Res.30(1), 56-71.

Mills, T.M., Showalter, E., Jarman, D., 1999. A cost-effective waste management plan. Cost Eng. 41(3), 35-43.

Mitchell, R.C., Carson, R.T., 1989. Using Surveys to Value Public Goods: The Contingent Valuation Method. Johns Hopkins University Press, Baltimore, MD.

Mitchell, R.K., Agle, B.R., Wood, D.J., 1997. Toward a theory of stakeholder identification and salience: defining the principle of who and what really counts. Acad. Manag. Rev. 22(4), 853-887.

Osmani, M., Glass, J., Price, A.D.F., 2008. Architects' perspectives on construction waste reduction by design. Waste Manag.28(7), 1147-1158.

Poon, C.S., Yu, A.T.W., Ng, L.H., 2001. A Guide for Managing and Minimizing Building and Demolition Waste. The Hong Kong Polytechnic University, Hong Kong.

Poon, C.S., Yu, A.T.W., Wong, A., Yip, R., 2013. Quantifying the Impact of Construction Waste Charging Scheme on Construction Waste Management in Hong Kong. J. Constr. Eng. Manag. 139(5), 466-479.

Sieffert, Y., Huygen, J. M., Daudon, D., 2013. Sustainable construction with repurposed materials in the context of a civil engineering-architecture collaboration. J. Clean. Prod.67, 125-138.

Skoyles, E.R., 1976. Materials wastage - a misuse of resources. Build. Res. Pract. 1, 232-243.

Walker, D.H.T., Bourne, L., Rowlinson, S., 2008. Stakeholders and the supply chain, in Walker,D.H.T., Bourne, L., Rowlinson, S. (eds), Procurement System: A cross-industry project management 
perspective, Taylor \& Francis.

Wang, J.Y., Li, Z.D., Tam, V.W.Y., 2014. Critical factors in effective construction waste minimization at the design stage: A Shenzhen case study, China. Resour. Conserv. Recycl. 82, 1-7.

Welp, M., de la Vega-Leinert, A.C., Stoll-Kleemann, S., Jaeger, C.C., 2006. Science-based stakeholder dialogues: Theories and tools. Glob. Environ. Chang. 16 (2), 170-181.

Wong, W., 2013. Government Denies dumping of imported waste. RTHK English News, 26-07-2013.

Yu, A.T.W., Poon, C.S., Wong, A., Yip, R., Jaillon, L., 2012. Impact of construction waste disposal charging scheme on work practices at construction sites in Hong Kong. Waste Manag. 33(1), $138-146$.

Yuan, H.P., Wang, J.Y., 2014. A system dynamics model for determining the waste disposal charging fee in construction. Eur. J. Oper. Res. in press.

Yuan, H.P., Lu, W.S., Hao, J.L., 2013. The evolution of construction waste sorting on-site. Renew. Sustain. Energy Rev. 20, 483-490.

Yuan, H.P., 2013. Critical management measures contributing to construction waste management: Evidence from construction projects in China. Proj. Manag. J. 44(4), 101-112.

Zhao, Z. Y., Zhao, X. J., Davidson, K., Zuo, J., 2012. A corporate social responsibility indicator system for construction enterprises. J. Clean. Prod. 29, 277-289. 


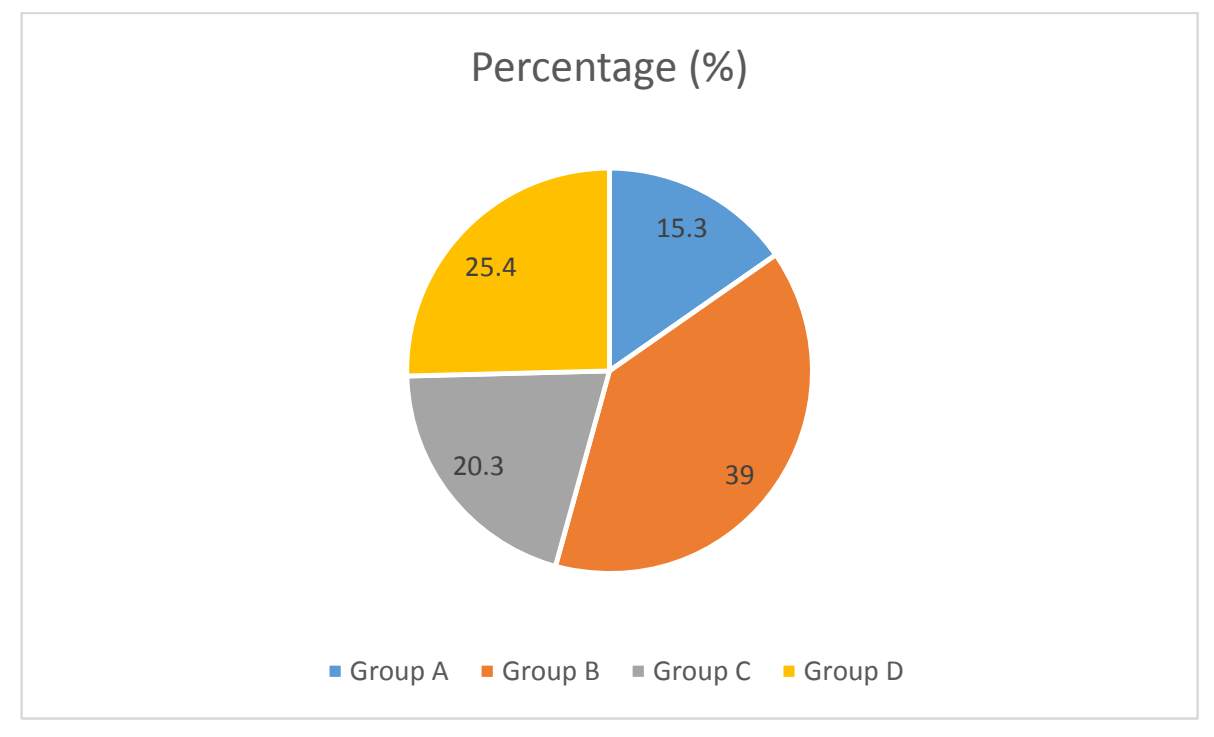

Figure 1 Percentages of questionnaire survey respondents 
Table 1 Stakeholders' willingness to pay values and their respective frequencies for $\mathrm{C} \& \mathrm{D}$ waste disposed of at landfills

\begin{tabular}{|c|c|c|c|c|c|c|c|c|}
\hline Maximum & Freque & of the & & & Percen & e of the & keholde & \\
\hline $\begin{array}{l}\text { WTP Value } \\
\text { (HK\$/ton) }\end{array}$ & $\begin{array}{l}\text { Group } \\
\text { A }\end{array}$ & $\begin{array}{l}\text { Group } \\
\text { B }\end{array}$ & $\begin{array}{l}\text { Group } \\
\text { C }\end{array}$ & $\begin{array}{l}\text { Group } \\
\text { D }\end{array}$ & $\begin{array}{l}\text { Group } \\
\text { A }\end{array}$ & $\begin{array}{l}\text { Group } \\
\text { B }\end{array}$ & $\begin{array}{l}\text { Group } \\
\text { C }\end{array}$ & $\begin{array}{l}\text { Group } \\
\text { D }\end{array}$ \\
\hline 100 & 1 & 2 & 2 & 1 & 11.1 & 8.7 & 16.7 & 6.7 \\
\hline 125 & 1 & - & - & 3 & 11.1 & - & - & 20 \\
\hline 150 & 1 & 2 & 2 & 4 & 11.1 & 8.7 & 16.7 & 26.6 \\
\hline 175 & 1 & 4 & - & - & 11.1 & 17.5 & - & - \\
\hline 200 & 1 & 3 & - & 3 & 11.1 & 13 & - & 20 \\
\hline 225 & - & 1 & - & - & - & 4.3 & - & - \\
\hline 250 & 1 & 9 & 3 & - & 11.1 & 39.2 & 25 & - \\
\hline 300 & 1 & - & 4 & 1 & 11.1 & - & 33.3 & 6.7 \\
\hline 350 & 2 & - & - & - & 22.3 & - & - & - \\
\hline 400 & - & 1 & - & - & - & 4.3 & - & - \\
\hline 500 & - & 1 & - & 3 & - & 4.3 & - & 20 \\
\hline 600 & - & - & 1 & - & - & - & 8.3 & - \\
\hline Total & 9 & 23 & 12 & 15 & 100 & 100 & 100 & 100 \\
\hline
\end{tabular}

"-" no indication of the WTP level from respondents 
Table 2 Stakeholders' willingness to pay values and their respective frequencies for C\&D waste disposed of at off-site sorting facilities

\begin{tabular}{|c|c|c|c|c|c|c|c|c|}
\hline \multirow{2}{*}{$\begin{array}{l}\text { Maximum } \\
\text { WTP Value } \\
\text { (HK\$/ton) }\end{array}$} & \multicolumn{4}{|c|}{ Frequency of the WTP } & \multicolumn{4}{|c|}{ Percentage of the stakeholders (\%) } \\
\hline & $\begin{array}{l}\text { Group } \\
\text { A }\end{array}$ & $\begin{array}{l}\text { Group } \\
\text { B }\end{array}$ & $\begin{array}{l}\text { Group } \\
\text { C }\end{array}$ & $\begin{array}{l}\text { Group } \\
\text { D }\end{array}$ & $\begin{array}{l}\text { Group } \\
\text { A }\end{array}$ & $\begin{array}{l}\text { Group } \\
\text { B }\end{array}$ & $\begin{array}{l}\text { Group } \\
\text { C }\end{array}$ & $\begin{array}{l}\text { Group } \\
\text { D }\end{array}$ \\
\hline 75 & 2 & 2 & - & - & 22.2 & 8.7 & - & - \\
\hline 100 & 1 & 3 & 1 & 5 & 11.1 & 13 & 8.3 & 33.3 \\
\hline 125 & - & 2 & 2 & 3 & - & 8.7 & 16.8 & 20 \\
\hline 150 & 3 & 5 & 1 & 2 & 33.4 & 21.8 & 8.3 & 13.2 \\
\hline 175 & - & 1 & 1 & - & - & 4.3 & 8.3 & - \\
\hline 200 & 1 & 4 & 6 & 1 & 11.1 & 17.5 & 50 & 6.7 \\
\hline 225 & - & - & - & 1 & - & - & - & 6.7 \\
\hline 250 & 1 & - & - & - & 11.1 & - & - & - \\
\hline 275 & - & - & - & 1 & - & - & - & 6.7 \\
\hline 300 & 1 & 3 & - & 1 & 11.1 & 13 & - & 6.7 \\
\hline 350 & - & - & - & 1 & - & - & - & 6.7 \\
\hline 400 & - & 1 & 1 & - & - & 4.3 & 8.3 & - \\
\hline 500 & - & 2 & - & - & - & 8.7 & - & - \\
\hline Total & 9 & 23 & 12 & 15 & 100 & 100 & 100 & 100 \\
\hline
\end{tabular}

"-" no indication of the WTP level from respondents 
Table 3 Stakeholders' willingness to pay values and their respective frequencies for C\&D waste disposed of at public fill reception facilities

\begin{tabular}{|c|c|c|c|c|c|c|c|c|}
\hline \multirow{2}{*}{$\begin{array}{l}\text { Maximum } \\
\text { WTP Value } \\
\text { (HK\$/ton) }\end{array}$} & \multicolumn{4}{|c|}{ Frequency of the WTP } & \multicolumn{4}{|c|}{ Percentage of the stakeholders (\%) } \\
\hline & $\begin{array}{l}\text { Group } \\
\text { A }\end{array}$ & $\begin{array}{l}\text { Group } \\
\text { B }\end{array}$ & $\begin{array}{l}\text { Group } \\
\text { C }\end{array}$ & $\begin{array}{l}\text { Group } \\
\text { D }\end{array}$ & $\begin{array}{l}\text { Group } \\
\text { A }\end{array}$ & $\begin{array}{l}\text { Group } \\
\text { B }\end{array}$ & $\begin{array}{l}\text { Group } \\
\text { C }\end{array}$ & $\begin{array}{l}\text { Group } \\
\text { D }\end{array}$ \\
\hline 0 & - & 1 & - & - & - & 4.3 & - & - \\
\hline 27 & 4 & 3 & - & 2 & 44.5 & 13 & - & 13.3 \\
\hline 50 & 1 & 6 & 5 & 7 & 11.1 & 26.2 & 41.7 & 46.6 \\
\hline 75 & 1 & 3 & 2 & - & 11.1 & 13 & 16.7 & - \\
\hline 100 & 2 & 4 & 3 & 1 & 22.2 & 17.5 & 25 & 6.7 \\
\hline 125 & 1 & 1 & - & 1 & 11.1 & 4.3 & - & 6.7 \\
\hline 150 & - & - & - & 1 & - & - & - & 6.7 \\
\hline 200 & - & 2 & 1 & 2 & - & 8.7 & 8.3 & 13.3 \\
\hline 400 & - & - & - & 1 & - & - & - & 6.7 \\
\hline 500 & - & - & 1 & - & - & - & 8.3 & - \\
\hline 600 & - & 1 & - & - & - & 4.3 & - & - \\
\hline 700 & - & 2 & - & - & - & 8.7 & - & - \\
\hline Total & 9 & 23 & 12 & 15 & 100 & 100 & 100 & 100 \\
\hline
\end{tabular}

"-" no indication of the WTP level from respondents 
Table 4 Statistics of maximum WTP of the four stakeholder groups

\begin{tabular}{|l|l|l|l|l|l|l|l|l|}
\hline & \multicolumn{2}{|l}{ Group A } & \multicolumn{2}{l}{ Group B } & \multicolumn{2}{l|}{ Group C } & \multicolumn{2}{l|}{ Group D } \\
& Mean & SD & Mean & SD & Mean & SD & Mean & SD \\
\hline Landfill & 222.22 & 94.74 & 225.00 & 86.93 & 254.17 & 133.92 & 231.67 & 146.83 \\
\hline OSFs & 161.11 & 77.17 & 205.43 & 123.39 & 189.58 & 75.72 & 168.33 & 82.63 \\
\hline PFRFs & 62 & 38.84 & 153.52 & 209.72 & 116.67 & 128.07 & 105.27 & 100.31 \\
\hline
\end{tabular}


Table 5 The results of the ANOVA analysis of four stakeholder groups' WTP

\begin{tabular}{|c|c|c|c|c|c|c|}
\hline & & $\begin{array}{l}\text { Sum of } \\
\text { Squares }\end{array}$ & $\mathrm{df}$ & $\begin{array}{l}\text { Mean } \\
\text { Square }\end{array}$ & $\mathrm{F}$ & $p$ \\
\hline \multirow{3}{*}{$\begin{array}{l}\text { Maximum WTP for C\&D waste } \\
\text { disposed of at landfills }\end{array}$} & Between Groups & 7883.004 & 3 & 2627.668 & .196 & .899 \\
\hline & Within Groups & 737180.556 & 55 & 13403.283 & & \\
\hline & Total & 745063.559 & 58 & & & \\
\hline \multirow{3}{*}{$\begin{array}{l}\text { Maximum WTP for C\&D waste } \\
\text { disposed of at OSFs }\end{array}$} & Between Groups & 19098.192 & 3 & 6366.064 & .647 & .588 \\
\hline & Within Groups & 541240.791 & 55 & 9840.742 & & \\
\hline & Total & 560338.983 & 58 & & & \\
\hline \multirow{3}{*}{$\begin{array}{l}\text { Maximum WTP for C\&D waste } \\
\text { disposed of at PFRFs }\end{array}$} & Between Groups & 59508.220 & 3 & 19836.073 & .839 & .479 \\
\hline & Within Groups & 1300955.339 & 55 & 23653.733 & & \\
\hline & Total & 1360463.559 & 58 & & & \\
\hline
\end{tabular}


Table 6 Average maximum WTP for enhancing CWM in Hong Kong

\begin{tabular}{|l|l|l|}
\hline \multirow{2}{*}{} & \multicolumn{2}{|c|}{ Total } \\
\cline { 2 - 3 } & \multicolumn{2}{|c|}{ Mean (HK\$) } \\
\hline Landfills & 232.20 & 113.34 \\
\hline OSFs & 186.02 & 98.29 \\
\hline PFRFs & 119.80 & 153.15 \\
\hline
\end{tabular}

